\title{
Language Sciences
}

\section{Maximality and idealized cognitive models: the complementation of Spanish tener}

\author{
Joseph Hilferty ${ }^{\mathrm{a}, *}$, Javier Valenzuela ${ }^{\mathrm{b}}$ \\ ${ }^{a}$ Departmento de Filologia Anglesa i Alemanya, Facultat de Filologia, Universitat de Barcelona, \\ Gran via de les Corts Catalanes 585, 08007 Barcelona, Spain \\ ${ }^{\mathrm{b}}$ Departmento de Filología Inglesa, Facultad de Letras, Universidad de Murcia, \\ Santo Cristo, 1, 30001, Murcia, Spain
}

\begin{abstract}
In this paper, we discuss the bare-NP complementation pattern of the Spanish verb tener 'have.' We show that the maximality of the complement NP is dependent upon three factors: (i) idiosyncratic valence requirements; (ii) encyclopedic knowledge related to possessions; and (iii) contextualized semantic construal. More specifically, we present evidence suggesting that whether such bare count-noun complements can be interpreted as maximal or not hinges on specific facets of world knowledge and morphosyntax: bare complement NPs that are usually possessed in numbers greater than one need a plural marker in order to be maximal; those that are usually possessed in quantities of only one need no such marking. This interpretation of the facts stands in direct contradiction with the Chomskyan notion of grammar as an autonomous module, isolated from general knowledge. Contrary to the autonomy thesis, we show here that encyclopedic-knowledge structures can play a significant role in syntax. (C) 2001 Elsevier Science Ltd. All rights reserved.
\end{abstract}

Keywords: Construction grammar; Idealized cognitive models; Integration of syntax and semantics; Maximality; Modularity; Verb complementation

\section{Introduction}

Most linguists would probably agree that the general notion of maximality (a.k.a. maximal projection in X-bar theory) is an intuitively good idea that, unfortunately, is fraught with many problems. Ironically, however, these difficulties are rarely ever addressed as such in the literature (but see Kornai and Pullum, 1990). In

\footnotetext{
* Corresponding auhor.

E-mail addresses: hilferty@lingua.fil.ub.es (J. Hilferty), jvalen@fcu.um.es (J. Valenzuela).
} 
this paper, we would like to "break the silence," so to speak, and discuss bare-NP complementation with regard to the Spanish verb tener 'have.' It will be shown that the maximality of tener's complement NP is dependent upon three interrelated factors: (i) idiosyncratic valence (i.e. subcategorization) requirements; (ii) idealized cognitive models pertaining to possessions; and (iii) overall semantic construal. From the intimate interaction of such disparate types of information, we conclude that a modular view of grammar cannot be taken uncritically.

\section{Idiosyncratic valence of tener}

The type of complementation pattern that we will be addressing in this paper can be found in example (1), where the complement of Spanish tener 'have' can be an undetermined singular count noun such as coche 'car': 1
(1) ¿Tienes
coche?
Have-you/sg
car
'Do you have a car?'

Undoubtedly, the fact that a sentence such as (1) is completely acceptable is a little strange, since bare singular count nominals are usually thought of as nonmaximal in Spanish. This can be seen by considering (2):

$$
\begin{array}{ll}
\text { a. }{ }^{*} \text { ¿Ves } & \text { coche? } \\
\text { See-you/sg } & \text { car } \\
\text { 'Do you see car?' } &
\end{array}
$$
b. * ¿Sabes
conducir
coche?
Know-you/sg
drive
car
'Do you know how to drive car?'

Given the distribution of grammaticality judgments in (1) and (2), it seems clear that what is a possible complement NP is directly related to the valence requirements of the particular verb. This will be an important intuition in our analysis.

Bearing the above observation in mind, we might, as a first attempt, state the valence of Spanish tener as in (3):
(3) TENER:
a. subj: $[\ldots]$
b. compl: [cat $n],[\max []]$

\footnotetext{
1 The fact that our examples take the form of questions does not preclude the use of this construction in declarative sentences (e.g. No te preocupes: ahora tengo coche 'Don't worry: I have a car now').
} 
The first thing to note in this preliminary representation is that there are two arguments: a subject [in (3a)] and a complement [in (3b)]. Because we want to concentrate on the complement argument, the subject argument will be left unanalyzed (hence, the square brackets with suspension points [...]). The second thing to note in this partial description is that tener takes a nominal complement (i.e. [cat $n$ ]); the analysis also says that the verb imposes no constraints on the maximality of this complement, since the value of this feature is left unspecified (i.e. [max [ ]]). In short, on this preliminary (straw-man) account, tener's valence requirements can unify with any nominal, irrespective of whether it is maximal or not.

Now, things would be perfect if maximality were merely an inherent property of the element that plays the complement role and not of the role itself. In what follows, we will show that this is an oversimplistic view of the problem.

\section{The ICM of generic possession}

The provisional account offered above is, unfortunately, a rather undesirable solution to the problem at hand. There are two reasons for this: first, it goes against the intuition that all arguments are maximal; and, second, it just will not work. Consider, for instance, the following examples:

$\begin{array}{ll}\text { a. }{ }^{*} \text { ¿Tienes } & \begin{array}{l}\text { moneda? } \\ \text { coin }\end{array} \\ \text { 'Dave-you/sg } & \\ \text { b. ¿Tienes have coin?' } & \begin{array}{l}\text { monedas? } \\ \text { Have-you/sg }\end{array} \\ \text { 'Do you have any coins?' } & \end{array}$

According to our tentative schema in (3), both of these sentences should be perfectly acceptable. However, only (4b) would normally be thought of as a grammatical utterance. Given that (4a) is formally parallel to sentence (1) ¿Tienes coche? 'Do you have a car?,' this is an unexpected result.

What could account for the difference in grammaticality judgments between examples (1) and (4a)? Obviously, the matter cannot be written down to a purely formal constraint, since both complements, coche 'car' and moneda 'coin,' share the same morphosyntactic information (i.e. they are both singular count nouns). The answer, instead, has to do with the kind of encyclopedic knowledge that we have about possessions. Following Lakoff (1987), we will call such knowledge constructs idealized cognitive models (henceforth, ICMs). ${ }^{2}$

The solution that we would like to propose is that, in Spanish, the ICM for generic possession has two logical possibilities: in one possibility, the possessed comes prototypically as discrete and uniplex (i.e. singular count nouns); in the other, the

${ }^{2}$ ICMs are functional equivalents of what Fillmore has called frames (cf. Fillmore 1975, 1985). 
possessed comes prototypically as discrete and multiplex (i.e. plural count nouns). ${ }^{3}$ On our account, it is this encyclopedic information concerning possessions that constrains tener's bare noun complementation, so that not just any count noun can be maximal.

The idea behind this explanation can be seen by analyzing the following example, in which tener takes a singular count noun as its complement:
a. ¿Tienes
marido?
Have-you/sg
husband
'Do you have a husband?'
b. *? ¿Tienes
maridos?
Have-you/sg
husbands
'Do you have husbands?'

In our prototypical view of marriage, couples are monogamous (cf. Fillmore, 1975). The possession relationship conveyed in (5a) makes use of this knowledge and, hence, the sentence is fully acceptable. Example (5b), on the other hand, is pragmatically very odd, since it goes against our marriage-ICM. The opposite situation can be found in (6):
a. * ¿Tienes
hijo?
Have-you/sg
child?
Do you have child?
b. ¿Tienes
hijos?
Have-you/sg
children?
Do you have children?

The reason behind the contrast in acceptability between (5) and (6) has to do with the fact that, in the ICM for parenthood, people prototypically have more than one child (at least, up till now). Hence, bare complements of the sort we have been discussing depend crucially on whether the number of the possessed is typically conceived of as plural or singular.

Fig. 1 is an attempt to formalize the solution just described. As can be seen, we are following a simplified version of Fillmore and Kay's construction grammar notation, which uses attribute-value matrices, or AVMs (cf. Fillmore and Kay, in press). Let us start by describing the left daughter in Fig. 1(a), corresponding to the lexeme tener. Here, the syn attribute takes as its value the syntactic category verb (note that the "..." merely means that the other information in this feature structure is irrelevant for our present purposes). In the sem attribute, we find the possession-ICM

\footnotetext{
${ }^{3}$ We simplify matters by disregarding mass nouns, which, their feature [num $s g$ ] notwithstanding, behave basically like plural count nouns (cf. Langacker, 1987b, 1990). The terms uniplex and multiplex are taken from Talmy (1988).
} 
(a)

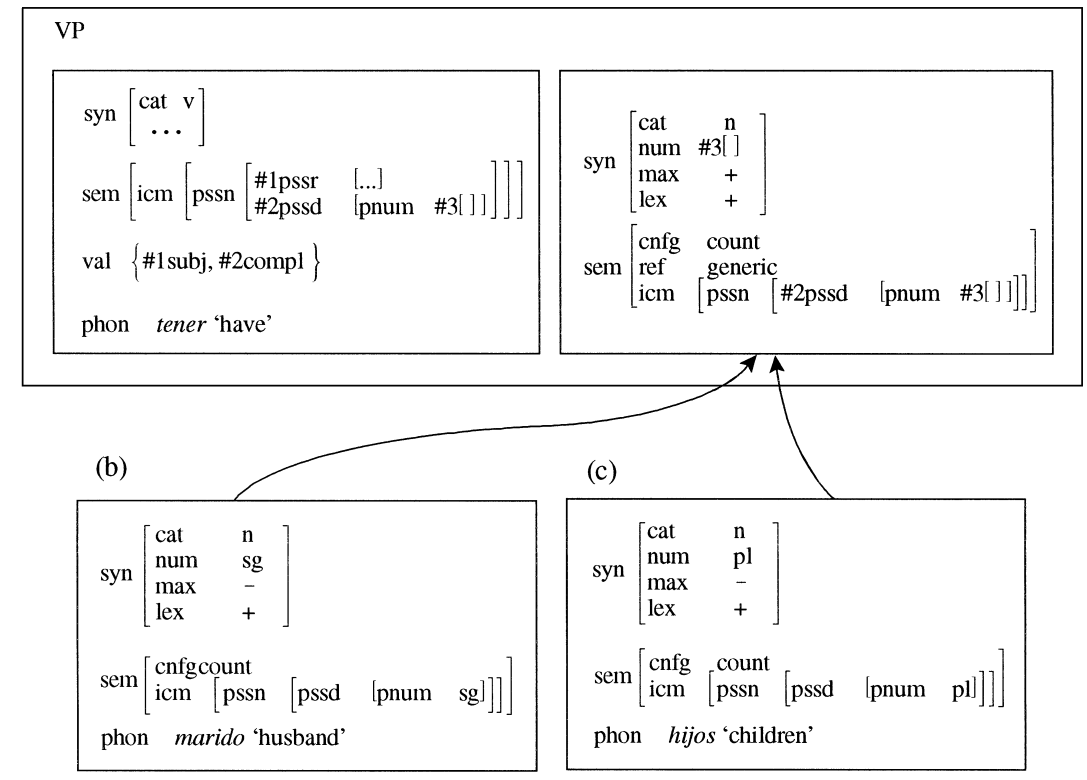

Fig. 1.

(possn), which has a complex internal structure. Being a relation, it has two participants: a possessor (possr) and a possessed (possd). The possessor is linked to the subject in the valence feature ( $\mathrm{val}$ ), which is indicated by index 1 . The possessed, on the other hand, is associated with the second element of tener's valence requirement $(\mathrm{compl}$ ) (see index 2). Note further that the possessed must satisfy certain restrictions regarding its number value. This is marked by index 3, which accompanies the unspecified value of pnum (possessed-number).

Turning to the right daughter of Fig. 1(a), ${ }^{4}$ we find that its syntactic category must be that of noun. The other three attribute-value pairs within the syn object are number (num), maximality ( $\max$ ), and lexicality (lex). The number value is coindexed to the pnum value located in the semantics of both the right and the left sisters: despite the fact that this value is left unspecified, index 3 ensures that, whatever the value is (necessarily, either singular or plural), it must coincide with that of pnum. The maximality attribute, on the other hand, has the value of + , meaning that it is a maximal projection. We come back to this feature below. Finally, the [lex +$]$ feature indicates that we are only dealing with bare nominals.

In the semantics of the right daughter, we have [cnfg count] and [ref generic], which is construction grammar's way of indicating that we are dealing with a count

\footnotetext{
${ }^{4}$ In a conventional construction grammar account, the information in the right daughter of this figure would occur directly in the valence requirements of the verb. We represent this information in a separate constituent for the sake of greater clarity.
} 
noun with generic reference (see Fillmore and Kay, in press). The relevant semantics of this constituent also includes information about the possession-ICM (possn), which unifies with the valence requirements of the left sister. Given indices 2 and 3, we know that this constituent is a complement of tener, whose semantic role is that of possessed and whose number can either be singular or plural.

As alluded to above, the pnum value of the possessed is coindexed with the value of the syntactic number (see index 3). The need for this coindexation can be clarified by comparing Fig. 1(b) and (c). Corresponding to Fig. 1(b) is the lexical form marido 'husband'. Syntactically, marido is of course a singular noun ([syn [cat n, num sg]). Note that in and of itself, marido is nonmaximal, as Spanish singular count nouns normally are. This is the case of the examples above in $(2)(*$ Ves coche? 'Do you see car?' and * ¿Sabes conducir coche? 'Do you know how to drive car?'). This is a very important point, because the maximality of the constituent is induced by the construction itself and is not carried over from the lexical form. The upshot of this observation is that, as we have already noted, maximality is not just a property of individual XPs in isolation from the heads on which they depend; rather it is a consequence of the generally accepted fact that "every non-head daughter in a rule is a maximal projection" (Kornai and Pullum, 1990, p. 31). From our perspective, this entails that maximality is a relational property that hinges on both the word instantiating the complement role and tener's valence requirements.

On the semantic side of things, marido 'husband' bears the attribute-value feature of [cnfg count], which simply means that it is countable. Of crucial importance is the pnum value, which in this case is singular $(\mathrm{sg})$. This falls out directly from our encyclopedic knowledge about marriage in Western societies, where the number of husbands allowed at any one time is of course one and only one. The same analysis can be applied to Fig. 1(c): in terms of our parenthood-ICM, the usual number of children in a family is more than one; hence, the lexical form hijos 'children' takes plural $(p l)$ as its pnum value. Given the above-mentioned unification constraint [indicated by index 3 in Fig. 1(a)], the fact that in both cases the values of pnum and num are the same is what licences the possible use of these words within the construction. This is also what blocks unacceptable examples such as (5b) * iTienes maridos? 'Do you have husbands?' and (6a) * ¿Tienes hijo? 'Do you have child?,' where syntactic number and pnum do not coincide.

\section{Alternative ICMs}

So far we have tacitly assumed that the words that fill tener's complement role have exclusively one possible pnum value. We shall see that this is not the case, however, since some possessions are able to appear in the singular or the plural. What this means is that the nominals in question allow for two different pnum possibilities: one in which the normal value would be singular, and another in which it would be plural. This ability to accommodate alternate values will turn out to be a very a productive mechanism in tener's bare-NP complementation. 
Of course, whether a speaker employs one or the other pnum possibility is not an arbitrary choice, but is instead highly context-dependent. Consider, in this connection, the utterances in (7):

$$
\begin{aligned}
& \text { a. ¿Tienes bolis? } \\
& \text { Have-you/sg pens } \\
& \text { 'Do you have pens?' } \\
& \text { b. ¿Tienes boli? } \\
& \text { Have-you/sg pen? } \\
& \text { 'Do you have a pen?' }
\end{aligned}
$$

The complements in sentences (7a) and (7b) take different number requirements because they pertain to different types of situations. For instance, (7a) could be felicitously uttered in the setting of a store, because stores, as a general rule of thumb, tend to stock supplies in quantities larger than single units. Example (7b), on the other hand, would have to be used in a situation in which a single pen would be the norm (e.g. taking notes in a classroom). The subtle differences in complementation are therefore intimately linked to differences in the underlying ICMs.

Up till now we have only discussed examples that draw upon conventional ICMs. Because of this, it might at first seem simple to find counterexamples to our proposal. However, we feel that such counterexamples would merely be apparent rather than real, given the fact that speakers often invoke what we might call ad-hoc ICMs. Take, for instance, sentence (4a): ¿Tienes moneda? 'Do you have (a) coin?' At first blush, this sentence seems odd, since it contradicts the knowledge implicit in our possession-ICM for coins: people normally carry more than one coin in their pockets. Nonetheless, it is possible to imagine a context in which this sentence would be a perfectly acceptable sentence. One case might be that of a teacher who takes his pupils to a fairground attraction requiring one coin per person. While standing in line, the teacher could perfectly well ask each child in his charge the question in (4a) in order to ensure that everybody is ready to get in. In such a situation, this example would automatically become acceptable.

The fact that utterances such as (4a) can change their acceptability status is not really all that surprising, since it reflects our cognitive ability to construct ad-hoc categories. As shown by Barsalou (1983, 1991), people have a remarkable ability to improvise nonconventional categories on the spur of the moment, according to their needs and purposes. In terms of the present analysis, this entails that the default values of any ICM can be overridden so long as they are consistent with the demands of context. Hence, what we do in these situations is to create an "on-line" ICM that we tailor to the specific situation in which the speech event takes place. It seems, then, that contextsensitive examples of this type do not falsify our analysis, but rather they confirm it.

\section{Conclusions}

Though this paper has merely scratched the surface of tener's complementation, we think that it has cast some light on several interesting issues. To start with, it has 
been shown that the Chomskyan notion of grammar as an autonomous module isolated from general knowledge is - to say the very least - overstated (cf. Hudson, 1984, 1990; Langacker, 1994). Contrary to the autonomy thesis, our data support the view that general-knowledge structures such as ICMs can in fact play a significant role in syntax. With regard to the complementation of Spanish tener, we have presented evidence suggesting that whether its bare count-noun complements can be construed as maximal or not depends directly on the interaction of the possession-ICM with morphosyntax: bare complement NPs that are usually possessed in numbers greater than one need a plural marker to be maximal; those that are usually possessed in quantities of one need no such marking.

If the details of the account proposed here are correct, the ramifications for standard $\mathrm{X}$-bar approaches to syntax are profound. Such approaches tend to view maximality as a property of XP constituents that is independent of valence requirements. In contrast, we argue that maximality is better construed as the satisfaction of multiple constraints that grammatical constructions place upon their individual components. This is in consonance with cognitive approaches to grammar (e.g., Kay and Fillmore, 1999; Lakoff, 1987; Langacker, 1987a, 1990, 1991; Fillmore and Kay, in press), and we believe it is in line with the facts presented herein. The challenge, then, is to stipulate just what conditions must be met for an argument or a modifier to be maximal. The data from this paper suggest that, in some cases at least, these conditions will not be entirely syntactic.

\section{Acknowledgements}

A version of this paper was read at the 5th International Cognitive Linguistics Conference, held 14-19 July 1997 in Amsterdam. We would like to thank Mar Garachana, Paul Kay, Anna Poch, and an anonymous reviewer for their advice. Of course, we alone are responsible for any and all errors that this paper might contain.

\section{References}

Barsalou, L.W., 1983. Ad hoc categories. Memory and Cognition 11, 211-227.

Barsalou, 1991. Deriving categories to achieve goals. In: Bower, G.H. (Ed.), The Psychology of Learning and Motivation: Advances in Research and Theory, vol. 27. Academic Press, New York, pp. 1-64.

Fillmore, C.J., 1975. An alternative to checklist theories of meaning. Berkeley Linguistics Society 1, $123-131$. Fillmore, C.J., 1985. Frames and the semantics of understanding. Quaderni di semantica 6, $222-254$.

Fillmore, C.J., Kay, P., in press. Construction Grammar. CSLI Publications, Stanford, CA.

Hudson, R.A., 1984. Word Grammar. Blackwell, Oxford.

Hudson, R.A., 1990. English Word Grammar. Blackwell, Oxford.

Kay, P., Fillmore, C.J., 1999. Grammatical constructions and linguistic generalizations: the What's $X$ doing $Y$ construction. Language 75, 1-33.

Kornai, A., Pullum, G.K., 1990. The X-bar theory of phrase structure. Language 66, 24-50.

Lakoff, G., 1987. Women, Fire, and Dangerous Things: What Categories Reveal about the Mind. University of Chicago Press, Chicago.

Langacker, R.W., 1987a. Foundations of Cognitive Grammar, vol. I: Theoretical Prerequisites. Stanford University Press, Stanford, CA. 
Langacker, R.W., 1987b. Nouns and verbs. Language 63, 53-94.

Langacker, R.W., 1990. Concept, Image, and Symbol: The Cognitive Basis of Grammar. Mouton de Gruyter, Berlin.

Langacker, R.W., 1991. Foundations of Cognitive Grammar, vol. II: Descriptive Application. Stanford University Press, Stanford, CA.

Langacker, R.W., 1994. Culture, Cognition, and Grammar. In: Pütz, M. (Ed.), Language Contact and Language Conflict. John Benjamins Publishing, Amsterdam, pp. 25-53.

Talmy, L., 1988. The relation of grammar to cognition. In: Rudzka-Ostyn, B. (Ed.), Topics in Cognitive Linguistics. John Benjamins Publishing, Amsterdam, pp. 165-204. 